\title{
La escuela, una organización ritualizada ${ }^{1}$
}

\author{
The School, a Ritualized Organization
}

\section{Agustín Escolano Benito²}

\section{Resumen}

\begin{abstract}
El presente trabajo trata de incorporar la historia de la escuela en el corriente de la historia cultural de la experiencia, mostrando como la cultura empírica se sustenta, además de en las prácticas que ejecutan alumnos y enseñantes, en los modos de sociabilidad que los actores de la educación formal llevan a cabo mediante las ritualidades que institucionalizan la educación formal. Analiza, bajo un enfoque esencialmente fenomenológico y antropológico, las formas que adoptan los rituales escolares de paso y de interacción, y como éstas contribuyen a asegurar la gubernamentalidad de la vida escolar. Se complementa con la nueva perspectiva de la historia de las emociones. El texto se ilustra con algunas iconografías que muestran ejemplos de algunos de los ritos más frecuentes en la cotidianidad de la experiencia escolar y sus relaciones con los mitos, los juegos y las ceremonias. También plantea las resistencias que las prácticas rituales ofrecen a los procesos de cambio en la educación formal.
\end{abstract}

Palabras clave: rituales escolares, cultura empírica de la escuela, modos de sociabilidad escolar, historia intelectual de la experiencia

\section{Abstract}

The present article is an effort to incorporate the history of the school into the cultural history of experience, thus showing how empirical culture is based - beyond the practices which students and teachers perform - in the ways in which actors of formal education socialize, through the rituals which institutionalize formal education. This paper analyses, essentially from a phenomenological and anthropological perspective, the ways in which school rituals of passage and interaction materialize, and how these contribute to sustain the governance of school life. This is complemented with the perspective of the history of emotions. This text shows some iconographies which show

\footnotetext{
${ }^{1}$ Este trabajo amplía y modifica el texto inserto en el editado por la profesora Teresa González Pérez en el colectivo Entre el olvido y la memoria. Educación, mitos y realidades, Valencia, Editorial Tirant, 2018, pp. 21-39.

2 Universidad de Valladolid y Centro Internacional de la Cultura Escolar ESPAÑA. Correo electrónico: aeb05@telefonica.net
} 
examples of the most frequent rites in the everyday life of school experience and their relation to myths, games and ceremonies. Finally, this article also puts forward the resistances which ritual practices offer toward the processes of change within formal education.

\section{Keywords: school rituals, empirical culture of the school, forms of socialization at the school, intellectual history of experience}

\section{La ritualización de la experiencia}

Este trabajo se inscribe en el contexto historiográfico de la cultura empírica de la escuela, que a la vez se inserta en la llamada historia intelectual de la experiencia, un amplio ámbito de orientación eminentemente fenomenológica y hermenéutica que acerca la historia de la educación a la antropología y a la etnografía. El contenido de este estudio se centra específicamente en el análisis de los modos de sociabilidad que informan este capítulo, poco estudiado, de la historia pragmática de la escuela.

Arrancaremos de las propuestas que nos sugieren las obras del sociólogo Richard Sennett en su conocida trilogía integrada por los libros intitulados El artesano, Juntos y Construir y habitar. Los tres afectan a cuestiones esenciales en la configuración de la historia de la experiencia en general, y de la experiencia educativa en particular. La primera obra sostiene como tesis central que en toda obra humana, incluidas las de naturaleza abstracta, opera siempre algún tipo de referencia material que es un anclaje que otorga estabilidad y duración a la experiencia. También apunta, como su correlato, que los actores que llevan a cabo esta acción social-material son artesanos, esto es, sujetos que tratan de hacer las cosas con tacto corporal, con intuición estética y con inteligencia práctica (Sennett, 2009, p. 21).

La segunda, que tiene que ver más con las cuestiones que se van a desarrollar aquí, plantea de forma empírica cómo la mayor parte de las construcciones materiales y culturales requieren algún tipo de sociabilidad, esto es, han de llevarse a cabo no individualmente sino entre varios individuos que trabajan juntos de forma coordinada. El autor ilustra la cubierta de esta segunda obra con el acto de la colocación de una escalera, mostrando cómo esta aparentemente simple tarea artesanal exige la intervención conjuntada de más de un operario. Aun dentro de su simplicidad, el montaje de la escalera es una acción compleja que pone en juego habilidades perceptivas y motoras que implican destrezas, acción coordinada, criterio estético y otras cualidades sociales.

La tercera alude a la ciudad como contexto en el que se dan las realidades que tratan las dos primeras y desemboca en propuestas para integrarlas de forma sustentable en la ciudad. 
Tal integración ha de conducir hacia una nueva ética de la ciudadanía que tiene también una fundamentación pedagógica.

Si de este ejemplo relativamente elemental pasamos a otras operaciones más complejas, y especialmente a las que bajo la forma de los modos de socialización mecánica, a los que se refirió Émile Durkheim, se han introducido para asegurar la gobernanza de instituciones sociales como la escuela, comprobaremos, en sus modus operandi, que se estas experiencias se organizan en prácticas rituales establecidas que entrenan y disciplinan los cuerpos de los sujetos intervinientes. Los códigos que ordenan las acciones cooperativas se plasman generalmente en coreografías visuales que afectan a los movimientos y gestos puestos en acción. Lo mismo sucede en otras situaciones como las bélicas o las religiosas, en los campamentos o en las iglesias. Guerreros y sacerdotes se comportan conforme a los códigos aceptados de una liturgia socializada que asegura el ejercicio del ethos que regula, en forma de protocolo o ceremonia, la vida en grupo (Sennett, 2009, p. 24).

La escuela asume igualmente esta lógica material y social. Se asienta en el proceder artesanal de sus actores, y se gobierna mediante dispositivos ritualizados que pautan, con reglas de sociabilidad en parte mecánicas, las relaciones entre sus actores y toda la experiencia comunitaria. Este trabajo aborda una de las características con las que se define la sociabilidad en la escuela, en lo que se refiere a los modos de gobierno de la institución y en lo que afecta a las relaciones formales y no formales de la interacción entre los sujetos que habitan en el establecimiento: su sentido ritual. Se inserta asimismo en el ámbito de la llamada cultura empírica de la escuela, constituida por el conjunto de prácticas que han configurado históricamente el modo de ordenar las acciones educativas y de pautar la gestión de los centros de formación, esto es, de regular los comportamientos que ejecutan los actores de la educación.

La cultura de la escuela, bajo esta perspectiva de la práctica, está asistida por una cadena de rituales interactivos que otorgan estabilidad y duración a los procesos formativos. Tales ritualidades se integran a la vez en el archipiélago de usos y costumbres, también rituales, en los que se organiza el mundo de la cotidianidad en que se inserta la experiencia escolar, en su contexto. La vida en las llamadas instituciones totales es, como estableció el antropólogo Erving Goffman, dramaturgia, ecología y juego (Goffman, p. 193). Ivan Illich, el autor de la intrépida y conocida tesis de la desescolarización, entrevió incluso que las escuelas, al igual que las iglesias, eran sistemas depositarios de los mitos de la sociedad, que institucionalizaban o encubrían las contradicciones y luchas entre la mitología y la realidad mediante rituales (Illich, p. 55). De este modo, los ritos no sólo cumplirían un papel funcional en la vida de las escuelas, sino también una finalidad antropológica y cultural.

La escuela como institución social alberga entre sus muros situaciones y acciones de copresencia que devienen en interacciones dinámicas, cuya sostenibilidad y continuidad depende justamente de la presión, tácita o explícita, que sobre los sujetos que intervienen 
en la experiencia compartida ejerce la fuerza cohesionadora y normalizadora del ritual, firmemente establecido en términos históricos por los usos sedimentados y por las costumbres sociales que lo crearon y acreditaron, y que lo han mantenido en tiempos de media o larga duración.

Más allá de los entornos materiales, la cultura de la educación se ritualiza en sus dimensiones corporativas. Así ocurre en los procesos de ingreso de los sujetos en la institución, y con las fases del desarrollo profesional de los docentes en la arena institucional, e incluso en la definición de los territorios que acogen a las tribus académicas y que marcan las reglas constitutivas de las disciplinas escolares. A los anteriores efectos, hay que hacer notar que las carreras docentes que siguen los enseñantes, así como los códigos curriculares y las jergas disciplinarias de que se sirven, son un buen ejemplo de cómo la cultura escolar ritualiza, para asegurar una determinada tradición en que instalarse y sustentarse, los modos de estructuración y funcionamiento de las comunidades científicas y educativas (Becher, pp. 16-18). Las etnografías y prosopografías de estas construcciones socioculturales constatan tradiciones, hábitos y prácticas que afectan al ethos de los actores, a las formas lingüísticas y simbólicas que comparten en los actos comunicativos y a las normas asumidas que regulan la existencia misma de las corporaciones docentes y la vida de las comunidades que sustentan los saberes que ofrecen a sus usuarios para ser cursadas en los establecimientos de enseñanza legítimamente reconocidos ${ }^{3}$.

Los espacios escolares serían, a los anteriores efectos, proscenios en los que se representa el drama de la experiencia educativa -el cursus del currículum - con sus correspondientes procesos de desarrollo y las acciones que implementan la mise en scène de la vida institucional. En ellos se enmarcan al mismo tiempo las relaciones de solidaridad intersubjetiva que se dan entre los sujetos. Cuando el rito se rompe -algo que puede pasar si se alteran gravemente las rutinas establecidas por la costumbre legalizada-, los actores acusarán sentimientos de inseguridad y hasta recibirán sanciones mientras el ritual se repone, esto es, mientras se restaura de nuevo el orden social que asegura la convivencia ceremonializada. Así lo argumenta el conocido antropólogo Randall Collins (Collins, p. 44 ss).

Casi todos los ritos, según señaló Edmund Leach, se generan en las encrucijadas que suponen un proceso de "paso" de una situación a otra: en nuestro caso, por ejemplo, en los pasos de niño a alumno, de la familia a la escuela, de un grado a otro... (Collins, p. 45). Tales tránsitos implican "separaciones" (desde los espacios o niveles de los que se procede) e "incorporaciones" (a los nuevos ámbitos sociales o a las acreditaciones de los diplomas que legalizan el cambio de grado o nivel). Como otros ritos, estos procesos se acompañan de ciertos juegos simbólicos que en el caso de la escolarización suelen consistir en la puesta en

\footnotetext{
${ }^{3}$ Ibidem, pp. 44-45.
} 
escena de situaciones sociales en las que se acompañan de himnos, banderas, saludos, juramentos de adhesión, oraciones, exámenes y otras mediaciones de carácter simbólico y formal que introducen cierta marca o señal de sacralidad en la liturgia institucional establecida. El carácter de transición puede adoptar a menudo modos de expresión próximos a las conductas lúdicas dramatizadas.

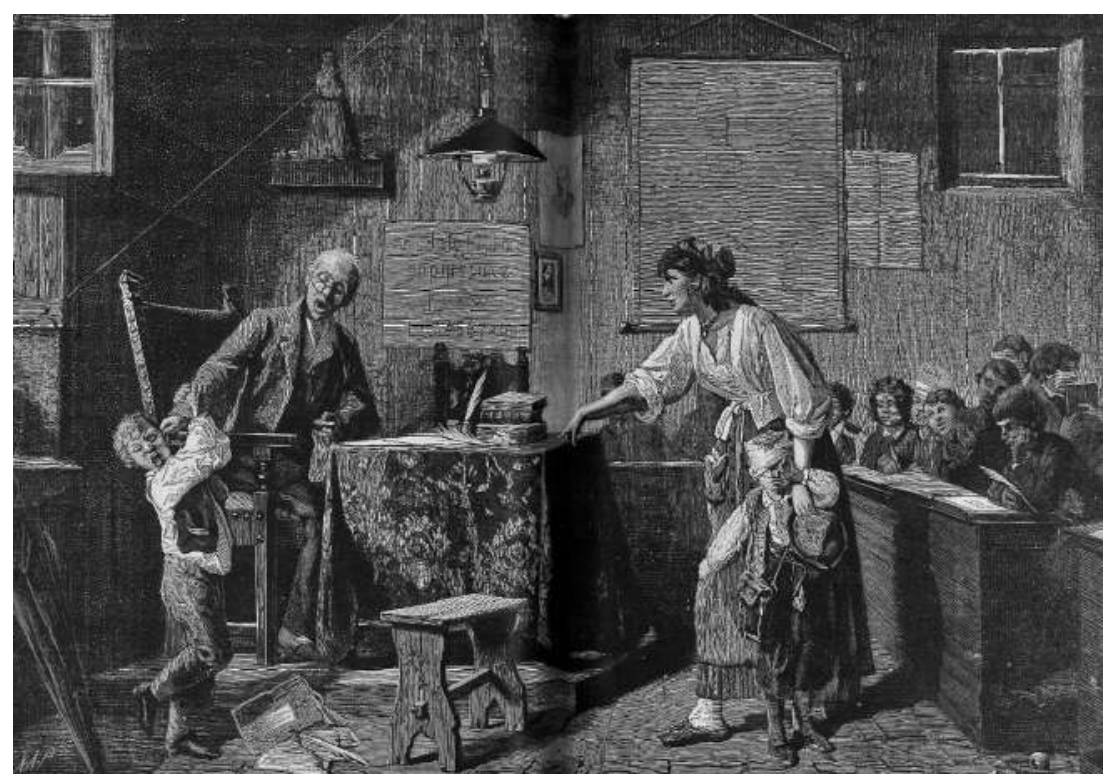

Imagen 1. Grabado alemán del XIX. Ingreso del niño en la escuela

\section{RITUAL DE INGRESO. RIGOR Y DRAMA}

El ingreso en la escuela es una de los ritos de ingreso que experimentan los sujetos al iniciarse en la vida escolar. Los rituales encauzan el hecho sacrificial de pasar de un régimen de vida a otro.

La imagen es un grabado de una escuela alemana de mitad del siglo XIX. Muestra el momento en que la madre acompaña al menor en el acto de presentación al maestro y de entrega a la escuela.

El maestro aplica, con severidad ejemplarizante, un rudo castigo a un alumno, mientras el nuevo escolar se resiste a ingresar en este régimen disciplinario. El paso de la convivencia doméstica, grata y lúdica, a la de las rudas disciplinas puede ser traumático.

Los demás alumnos observan desde sus bancos la escena, que ellos mismos ya han sufrido con anterioridad, y asumen las reglas rituales que socializan el drama. 


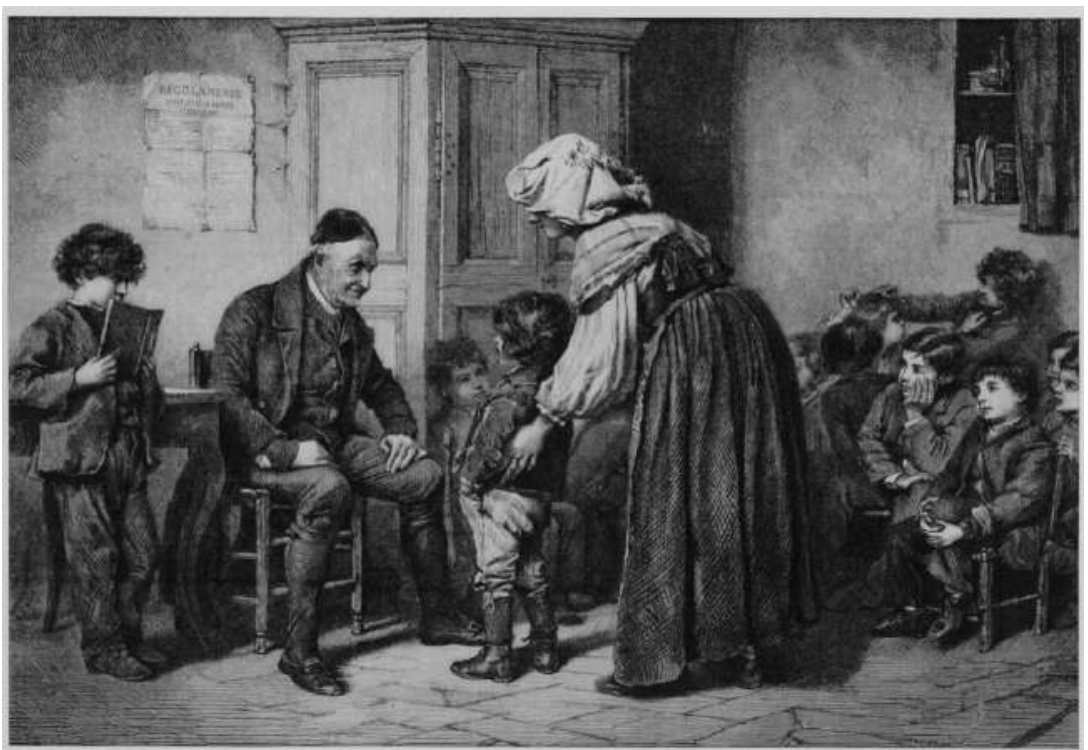

Imagen 2. Escuela italiana del XIX. Ingreso del niño en la escuela

\section{RITUAL DE INGRESO. ACOGIDA AMABLE}

Escena de una escuela romana popular a mediados del siglo XIX. La madre acompaña al niño el primer día de clase.

El clima emocional de esta escuela es menos disciplinario que el anterior. Las culturas latinas han sido, en general, menos rigurosas y puritanas que las adscritas a la ética protestante, lo que queda ejemplificado en el grabado alemán anteriormente mostrado.

En esta escenografía también hay un ritual implícito. La madre acompaña al menor y el maestro lo acoge con actitud paternal. Los niños, que serán los pares de edad del neófito, acompañan la ceremonia con el porte expectante y la mirada atenta.

En el muro aparece el reglamento de la escuela, a cuyas normas -también ritualeshabrá de sujetarse el nuevo alumno para asegurar la convivencia.

Pierre Bourdieu ha subrayado la fuerza reproductora de estas prácticas rituales conforme a las reglas aprobadas o asumidas, explícita o implícitamente, por el grupo. Comprender una práctica ritual es en buena medida "reconstruir su lógica interna" y reconocer las claves de su "necesidad práctica" (Bourdieu, 2007, 154 ss). Acceder al conocimiento de su genealogía, de su procesualidad en secuencias temporales irreversibles, así como de los juegos miméticos que regulan el aprendizaje de las reglas que informan las prácticas estructuradas como ritos, 
es acercarse a la construcción de una teoría de la práctica, en la que siempre subyace el discurso de la experiencia y la lógica de la eficacia social de este tipo de racionalidad empírica y pragmática.

El disco duro de la denominada "gramática de la escuela", protegido por los códigos del ritual, mantiene estable el orden de la cultura institucional y ofrece resistencia a los cambios que se suscitan como presión desde el exterior. Innovar la escuela exige casi siempre romper con las claves de la ritualidad establecida, lo que no es fácil, toda vez que la intervención externa podría ser percibida como una amenaza para todo el sistema vigente. La ruptura de la gramática genera inseguridad y esto no es fácilmente asumido ni por el grupo ni por los individuos que se han socializado en las reglas aprendidas y aceptadas que conforman su normalización. Es por esto justamente por lo que resulta tan complejo tratar de romper los lazos sociales que vinculan a los actores que intervienen en la representación del drama escolar durante los procesos de reforma educativa. Cambiar la práctica de la escuela implica siempre cambiar sus ritos establecidos, y este tipo de cambios que afecta a dispositivos tan fuertemente estructurados en la praxis requiere generalmente un nuevo consenso entre los sujetos o actores que participan en las acciones ordinarias que se desempeñan en el vivir cotidiano de las instituciones de formación. Toda innovación demanda además nuevos tiempos, que suelen ser de una cierta duración, a fin de poder asimilar durante el proceso de acomodación el sentido sociocultural de los cambios propuestos y sus consecuencias en lo que afecta a las reglas y condiciones de convivencia asumidas hasta entonces por la mayoría del grupo.

Algunos críticos de la nueva historiografía de la educación han advertido el posible riesgo de conservadurismo que subyace con la insistencia que se hace en la memoria y la tradición como elementos estructurantes de los códigos de la gramática de la escuela, vistos desde una perspectiva histórica antropologizada. Igualmente se ha querido hacer notar el peligro de considerar los rituales escolares como mecanismos invariantes. Conviene sin embargo subrayar a este respecto que los protocolos de los ritos sí pueden someterse a cambios, aunque esto sólo se logrará hacer con efectividad mediante amplios consensos, acuerdos que han de operarse en el clima democrático de las instituciones donde realmente se quieren implantar las mudanzas, no en las oficinas de las burocracias del sistema, ni tampoco en los departamentos académicos en los que se diseñan las innovaciones. Entre las estrategias de inducción de un cambio que se pretende sea viable pueden ponerse en marcha operaciones de diálogo como aquellas que algunos han definido como coaliciones de discursos y de prácticas, es decir, como concertaciones que permitan pactar entre los actores intervinientes nuevas reglas para ensayar modos y procesos que faciliten la innovación y para romper con ciertas estructuras que residen en los anclajes bien consolidados de la cultura vigente en las escuelas. 


\section{Ritual social y teoría/práctica de la escuela}

En relación a todo lo anterior, es importante comprender e interpretar la cultura de la escuela desde los ejes esenciales de la teoría y la práctica del ritual social, que el antropólogo Erving Goffman resumió en los cinco puntos que resumimos:

a) Todo ritual posee mecanismos de vigilancia tácita que operan como dispositivos de resistencia ante cualquier amenaza de cambio o transgresión que atente al funcionamiento de los sistemas regulados como espacios públicos. La escuela es uno de estos escenarios sistémicos dotados de importantes mecanismos de autocontrol y heterocontrol, y los profesores se autorregulan mediante sus reglas propias de cohesión corporativa que tienen que ver con la gramática establecida y con su habitus profesional.

b) El modelo dramatúrgico, del que nos estamos sirviendo aquí en ocasiones, no es sólo una metáfora retórica que sobrevuela el análisis representacional de la vida escolar, sino un paradigma que comparte este modo de representación. En el proscenio se ejecuta el ritual (mise en scène), pero las claves de lectura del mismo siempre están en el trascenio. Esto mismo ocurre en la interacción escolar, en la que tras las bambalinas del teatro visible de la clase se ocultan los dramas subjetivos que viven los actores, que no obstante pueden ser traídos de nuevo a escena para su abordaje lúdico-representativo. Las coaliciones de discurso antes aludidas podrán ser abordadas a través de estos juegos interactivos de actores que representan intereses contrapuestos, aunque también negociables.

c) Los rituales presionan para mantener la solidaridad orgánica o formal entre los sujetos que comparten sus vidas e intereses en las instituciones en las que conviven o interactúan. La aquiescencia a este ordenamiento es en realidad una prueba de la cohesión social de la institución. En nuestro campo de análisis, los protocolos ritualizados de la praxis escolar funcionan bajo estas expectativas prefijadas que aseguran una cierta solidaridad mecánica entre todos los miembros de una comunidad, según reglas que ya aplicó hace tiempo a otros contextos el sociólogo Émile Durkheim.

d) Los ritos sacralizan los valores socialmente asumidos. Incumplirlos es romper con elementos que forman parte de una cierta mitología que legitima las instituciones. La escuela es una institución social que se sustenta en mitos como los del progreso, la cultura, la autoridad y la democracia. Atentar contra los rituales que refuerzan estos mitologemas, que tienen un poder estructurante, puede abocar a cuestionar y a poner en riesgo los discursos de quienes sostienen las instituciones como dispositivos orientados a apoyar la evolución de las sociedades hacia mundos que se supone van a ser mejores y más coherentes.

e) El ritual sustenta y refuerza la sensación de orden, y su restauración, cuando se ha roto o puesto en peligro, apoya ese sentimiento de racionalidad y seguridad que armoniza la 
vida en convivencia. La escuela es una organización sistémica sujeta a normas que ordenan el comportamiento de sus agentes y las interacciones con el contexto. Nadie imagina una institución educativa sin esta moral de orden y disciplina, que es la clave de su funcionamiento y de su desarrollo (Collins, 45). Los ensayos de escuelas anómicas, sin rituales reglados, han evolucionado siempre o hacia su disolución o hacia la búsqueda de algún otro tipo de orden.

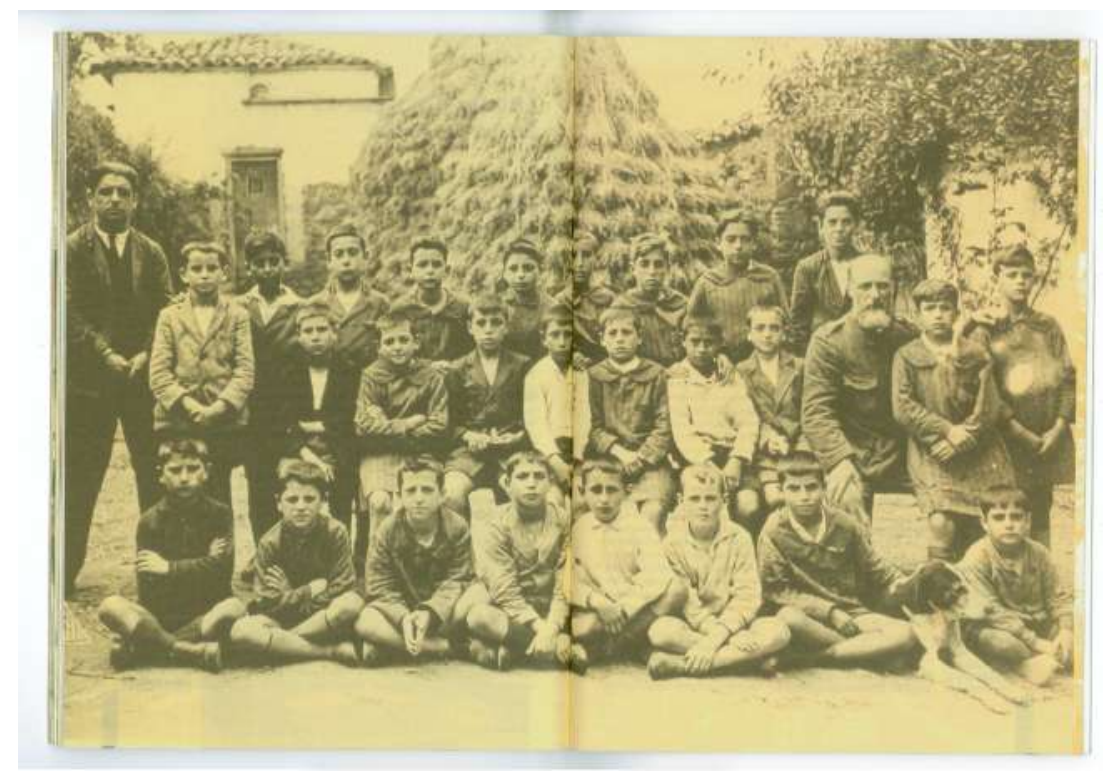

Imagen 3. Escenografía de escuela rural de Galicia, España. Comienzos del siglo XX

\section{COREOGRAFÍA RITUAL}

Escena de una escuela rural de Galicia, España, datada en los primeros años del último siglo, que puede ser representativa de la sociabilidad mecánica que, con carácter ritual, cohesiona a los niños y maestros de una institución como grupo con identidad sujeto a reglas comunes de convivencia y a lazos afectivos solidarios.

El mismo tipo de imagen podría repetirse en muy diversos lugares del país y de otras regiones del mundo porque es característico de la impronta que la cultura escolar otorga a los colectivos que se educan en ella y que se inician en sus ritualismos.

Obsérvense los niños colocados en tres filas, que corresponden a los tres grados o niveles de instrucción a que se adscriben los sujetos. También es significativa la situación del maestro y de su auxiliar a uno y otro lado de la escena, enmarcando y tutelando 
el conjunto del grupo. Nótese asimismo el detalle de la presencia del perro al pie de la foto, símbolo de su papel como guardián y amigo de todos.

Este tipo de coreografía es una práctica generalizada en la mayor parte de las escuelas desde que se popularizó la fotografía, y es una fuente historiográfica que acredita la impronta ritual de la vida en las instituciones.

Además de lo anterior, la cultura de la escuela se desenvuelve en el mundo de la vida y en los contextos que lo integran, un ámbito global que está constituido a la vez, como señala Rodrigo Díaz, por un complejo "archipiélago de rituales" (Díaz, p.181). Son numerosas las relaciones sociales que tienen que ver de una u otra forma con la educación que están ritualizadas. No sólo se constatan estos hechos en los conocidos ritos de paso que acompañan a los procesos de edad y de identidad de los sujetos y grupos humanos, que están sometidos a tránsitos y lenguajes muy ceremonializados. Otros muchos aspectos de la vida social, no tan estructurados, se encuentran igualmente marcados por comportamientos rituales. Los tiempos y los procesos comunitarios que afectan al ordenamiento de lo escolar, la circulación por los espacios de la casa o de la escuela, la entrada en el trabajo, los juegos que llenan los ocios de los niños y mayores, las relaciones interclasistas y de género... Todas las acciones que tienen que ver con lo anterior se llevan a cabo según formalidades y protocolos explícitos o supuestamente asumidos por los sujetos que comparten las experiencias formativas.

De esta suerte, el mundo de la vida es un archipiélago de ritos entre cuyos islotes y mares circulan los individuos que se educan al tiempo que se socializan, en cuyo complejo magma se inscribe la escuela, que a la vez se regula, según hemos mostrado, conforme a específicas ritualidades. Esta organización de las sociedades, tradicionales o modernas, tiene una importante función de equilibrio y de conservación o estabilidad de los colectivos y de los individuos, como destacó hace tiempo el etnólogo Max Gluckman, en la medida en que tratan de evitar las disrupciones y conflictos que pondrían seriamente en peligro la misma existencia de los grupos humanos constituidos y estructurados (Gluckman, p. 194).

Desde los anteriores análisis, hasta las rutinas más elementales que conserva la organización escolar son piezas esenciales para el mantenimiento de la gramática interna de las instituciones. Los dispositivos de la aborrecida escuela que denunciaron Zweig y Pennac, en los narratorios literarios comentados ya conocidos, se adscriben -nos gusten o no- al núcleo duro que anuda y fija las llaves de la misma existencia de la escuela, amenazadas cuando desde el exterior se provocan cambios radicales que pueden afectar a la existencia de tan vetusto ordenamiento sociocultural y pedagógico. En tales situaciones, la institución educativa, por instinto de supervivencia, lucha por mantener su identidad mediante la defensa a ultranza de sus ritualidades básicas, las que poseen un alto poder orgánico y sistémico, que sólo 
podrán ser cambiadas si se negocian nuevos códigos de sociabilidad con los que poder seguir conviviendo.

Es esta a la vez una estrategia que viene acreditada por la misma experiencia histórica de constitución y pervivencia de las comunidades artesanas. La cultura práctica de la escuela se transmite y circula entre los docentes a través de diversos cauces de sociabilidad profesional, y también cultural. Richard Sennett insistía, en la obra referida al principio, en la asociación que se da siempre entre un oficio, los modos de comunicación del mismo y su forma de inserción en la comunidad. Las reglas y habilidades que definen la cultura de un arte u oficio se trasmiten de generación en generación, y no siempre -o no solamente- por vía académica. La sociedad y sus microestructuras familiares o contextuales han transmitido a la escuela, desde sus ámbitos específicos, prácticas empíricas de cultura, muchas de las cuales han pasado a formar parte del repertorio de acciones que constituyen las tramas operativas de la enseñanza y los modos de aprendizaje.

Sennett complementó el título de su obra Juntos con el subtítulo Rituales, placeres y política de cooperación. La cooperación, según él, es un valor universal que se plasma sobre todo en los ritos, ya sean estos sagrados o seculares. Los rituales de civismo ponen en práctica las manifestaciones del mutualismo que anidan en los genes de todos los animales sociales, según han analizado los etólogos. Adquirir estas que hoy llamaríamos "habilidades sociales" es, como en su tiempo habría dicho Aristóteles, incorporar a nuestras conductas una tékhne política que se aprende, necesaria e imprescindible para poder convivir juntos. Estos hábitos se adquieren en las primeras adaptaciones al contexto concreto en que se habita; más tarde, con el proceso de la evolución en marcha, los dispositivos aprendidos se pueden de nuevo negociar. A estos efectos, ha de hacerse notar que aprendemos antes a "estar juntos" que a separarnos (Sennett, 2012, p. 20).

Los rituales se ejecutan mediante ceremonias que vienen dictadas por la tradición y que han de ser cumplimentadas correctamente. Puede incluso que tales comportamientos se ejecuten con placer: los niños gustan de los saludos, exageran a veces las reverencias, acatan con entusiasmo determinadas conductas rituales y memorizan los atractivos lenguajes de los mitos. El rito limita la agresividad entre los humanos, canaliza las emociones y ofrece un marco de referencia en las interacciones seguras. Viene determinado por la costumbre o la autoridad que lo legitima y es asimilado individualmente y en grupo a través del entrenamiento social o del juego.

Ahora bien, el ritual no es un comportamiento fijado de una vez para siempre, como se ha advertido antes. Está abierto a la evolución, aunque el cambio sea siempre lento y a menudo requiera relevos generacionales, como con acierto destacó Clifford Geertz (Geertz, p. 130). Así sucede también en la convivencia en la escuela. Alumnos y maestros se acomodan, para poder vivir "juntos", a las reglas establecidas por la tradición o la costumbre, que se 
internalizan en cuanto los sujetos se incorporan a la comunidad educativa. Los niños gustan asimismo de los rituales que repiten, a modo de protocolo bien pautado, ejecutado de forma lúdica pero con el debido rigorismo. Incluso cuando los menores los critican o los valoran con ironía, la disciplina o el humor de que se sirven facilitan siempre la asunción general de los obligados ceremoniales que requieren la cooperación solidaria entre los alumnos y los adultos, así como entre los pares generacionales.

Pues bien, la cultura empírica de la escuela está en gran medida formada por una cadena de rituales internos de interacción, y condicionada al mismo tiempo por las ritualidades del mundo de la vida que operan en el contexto influyendo sobre las instituciones de formación. Este sistema de ritos posee además un alto poder organizador y en su operatividad juega a veces como un dispositivo de resistencia a la innovación, de tal suerte que los cambios que afectan al núcleo fuerte o duro del sistema de vida escolar han de buscar, como antes se ha dicho, estrategias para poder convenir, con la oportuna inteligencia social, las nuevas propuestas con los patrones culturales que determinan la tradición y las prácticas dominantes.

La larga persistencia de las pautas rituales tiene que ver con la prolongada duración de determinadas prácticas de la cultura educativa, algunas de ellas anteriores incluso a la creación, a mediados del siglo XIX, de las escuelas normales, instituciones que quisieron imponer un nuevo modelo uniforme de organización pedagógica a todos los establecimientos de formación, y que no siempre lograron, o no en su globalidad. No obstante, como advirtió Narciso de Gabriel, para el caso de España, antes de que las escuelas quisieran normativizar los dispositivos de la vida escolar existía una pedagogía popular que, en parte al menos, sobrevivió largo tiempo en las prácticas cotidianas de las instituciones, más allá de las estrategias de ordenación que propició el estatismo liberal del siglo XIX. De Gabriel ha destacado que no son sólo los enseñantes, los pedagogos o los políticos quienes construyen normas para regular la enseñanza; también la comunidad y las familias propusieron pautas y métodos que se transmitieron en los colectivos de sociabilidad no formal y en la misma escuela (Gabriel, p. 243). Esta cultura formativa, de origen popular, es una especie de pedagogía folc que se materializó en acciones que se socializaron a través de la comunicación ritualizada de la tradición y que no se extinguieron bajo la presión externa de la cultura oficial o académica dominantes (Escolano, 2008, p. 158 ss). Comprender cómo la escuela acogió estas pautas civilizatorias es asumir de nuevo el importante papel que los rituales de la educación y las costumbres asociadas a estos han tenido en la construcción histórica de la cultura escolar.

En el marco del universo interno de la escuela, la transmisión de las artes empíricas y del ethos que su práctica comporta se lleva a cabo mediante procesos sociohistóricos que tienen que ver con el carácter ceremonial de toda la educación institucional. Aída Terrón y Violeta Álvarez, en su trabajo acerca de la interpretación de la cultura de la escuela en clave antropológico-cultural, proponen una teoría que conviene retomar aquí. Las autoras 
de este estudio sugieren que tanto los elementos extrasomáticos de esta cultura (concretados en el utillaje material en que se objetivan) como los intersomáticos (reflejado en las relaciones intersubjetivas de los cuerpos) conforman patrones de comportamiento institucional. Tales componentes poseen un importante poder modelador y recursivo y no son sólo variables de una pragmática meramente instrumental, toda vez que tanto el utillaje ergológico o de trabajo de los maestros como los dispositivos ceremoniales de que se sirve la ritualidad de la vida escolar configuran, en términos antropológicos, una cultura con peculiares señas de identidad (Terrón y Álvarez, p. 237 ss). Historia material e historia social de la educación encuentran en este planteamiento un campo definido de convergencia. Y en esta sinergia, la ritualidad de los hechos formativos es esencial. Los enseñantes, que ejercen de maestros de ceremonias, lo hacen habitualmente acompañados de los artefactos con los que ejercen su oficio.

La cultura empírica de la escuela, según hemos venido reiterando, tiene por tanto un fuerte carácter ritual. Se representa en acciones sostenidas para asegurar el orden y la gobernabilidad de los centros con que gestionan los profesores la vida en las aulas, según reglas que se mantienen a menudo a lo largo de diversas generaciones, y que se aplican en la mayor parte de los establecimientos. La ceremonia es una especie de categoría ecológica, de la misma naturaleza que el rito, que se propaga por los mecanismos habituales de transmisión de la tradición (apropiación, imitación o reproducción). Por su determinación cultural, más allá de lo propiamente etológico, las ceremonias escolares implican no sólo las rutinas que ya señalamos sino también mitologías, y por consiguiente una cierta sacralización de los lenguajes que regulan los conflictos que subyacen en toda comunicación humana (Bueno, pp. 8-34). Conviene recordar que la cooperación de la que habla Richard Sennett no sólo se resuelve en consensos, sino que también se adscribe al encauzamiento de los inevitables conflictos.

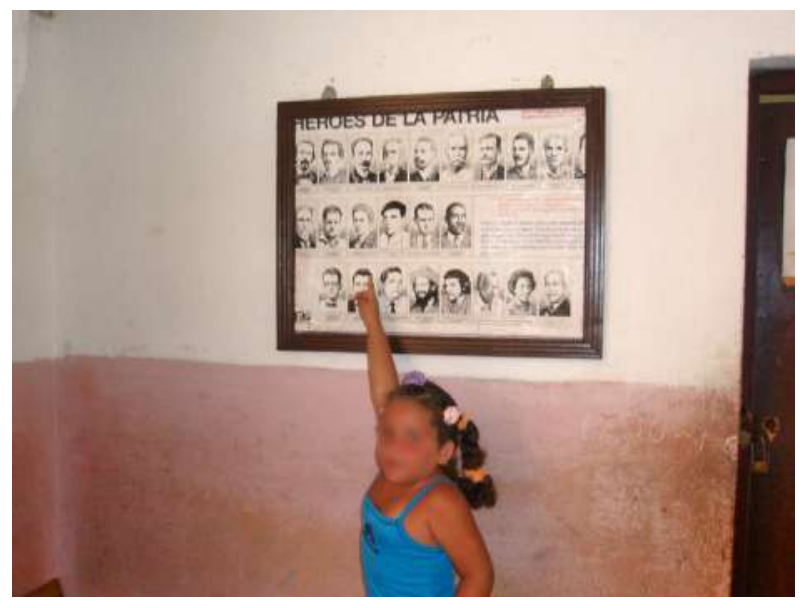

Imagen 4. Escuela actual de La Habana. La niña honra a los héroes de la patria 


\section{MITO Y RITUAL}

La transmisión de los mitos adopta casi siempre formas rituales que se insertan en el mismo espacio de la escuela.

La escena muestra una escuela de La Habana, Cuba, datada en 2007. La niña señala con su dedo índice el cuadro de honor en el que aparecen representados los "héroes de la patria", a quienes la menor rinde tributo ritual a diario.

En un texto del cuadro se lee: "Hay un límite al llanto sobre las sepulturas de los nuestros, y es el amor que se mira sobre sus cuerpos... y que no se debilita jamás, porque los cuerpos de los mártires son el altar de la honra".

La arquitectura escolar sirve aquí de soporte ritual al mito, propiciando la visibilidad cotidiana de los personajes mitificados.

Las ceremonias -según destacó el conocido antropólogo Jack Goody - no son sólo una forma del ludus, sino un patrón que modela todas las relaciones humanas en el trabajo (Goody, p. 118). Asociadas con la mímesis, las formas rituales teatralizan en cierto modo el drama de la convivencia, es decir, parodian la tragedia. En la escuela, algunos ritos regulan, con la liturgia asumida implícita o explícitamente por el colectivo afectado, el conflicto de la necesaria y obligada convivencia entre los mayores y los menores, así como de la competitividad entre los pares de edad, dos procesos de socialización que son esenciales en todas las comunidades y que pueden ser fuente de conflictos.

Gran parte de las conductas que alumnos y profesores ponen en práctica en las escuelas están sujetas a este formalismo ceremonial que caracteriza a todo el régimen de la institución educativa. Secuencias en cadena, programadas una tras otra, constituyen una especie de protocolo ritual prefijado y asumido por todos los afectados como dispositivos orientados a la normalización de la vida escolar. Esa organización, con escasas variantes, se repite de escuela en escuela y de generación en generación, en contextos sociales variados y en ciclos temporales durables. Los docentes serían, a estos efectos, oficiantes (sacerdotes laicos) de estas cadenas rigurosamente metodizadas de los procesos ceremoniales. 


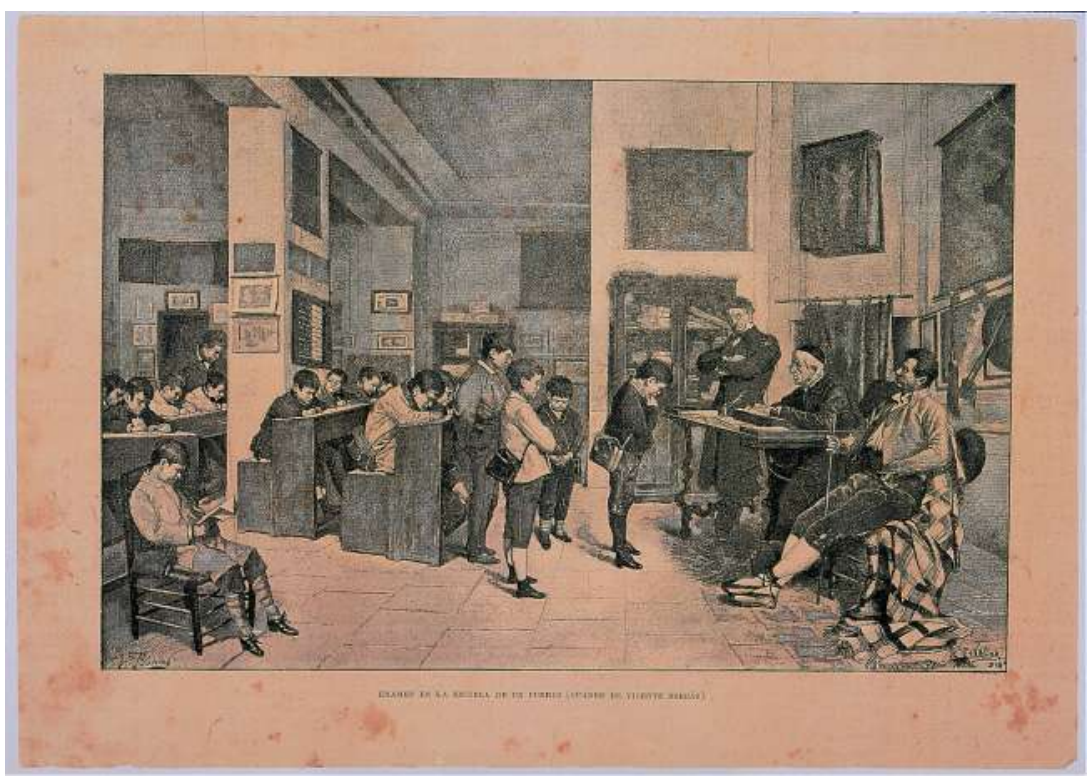

Imagen 5. Escena de examen público en una escuela de Aragón del siglo XIX, España

\section{EL RITO DEL EXAMEN PÚBLICO}

Los exámenes escolares son seguramente las situaciones más fuertemente sujetas a la lógica del control social y por tanto las más ritualizadas.

La imagen que se ofrece, de finales de la mitad del siglo XX, muestra la ceremonia de una jornada de evaluación escolar.

Los niños son sometidos periódicamente a examen un público que permita acreditar socialmente sus aprendizajes, ante el maestro y ante las autoridades locales que asisten para legitimar el acto y para constatar los resultados de las escuelas.

La escenografía pone en imagen la ceremonia del examen: el escenario, los actores, la performance de la actuación. Responde al modelo de una coreografía con los elementos dispuestos como en un proscenio teatralizado.

Las escenografías de la escuela -algunas de ellas verdaderos montajes afines al pictorialismo fotográfico, en varias ocasiones ficticios- han mostrado las representaciones ideales o reales de estos pasos del ritualismo pedagógico: niños bien alineados formando coreografías; enseñantes ejerciendo de maestros de ceremonias en actitudes claramente identificables y 
reproducibles (señalar, preguntar, examinar, corregir, castigar, tutelar...); sujetos agrupados y ordenados en niveles, en escalera, en filas, en grupos de acción, en hileras de pupitres... Toda esta rutina ceremonial, siempre presente en la vida cotidiana de todas las escuelas, de las antiguas y de las modernas, aproxima su cultura subyacente a la retórica de las representaciones, igualmente sujeta a la lógica de los escenarios, de los tiempos y de las acciones que se repiten en todas y cada una de las sesiones. En definitiva, cada ritual podría ser representado en una especie de puesta en escena, más o menos estereotipada y común, que los actores implicados reconocen, comparten, mimetizan y comunican. Y este reconocimiento colectivo de las ritualidades es la mejor prueba del carácter cultural que tienen las coreografías y los contenidos seleccionados que en ellas se representan.

Algunas de las imágenes que se utilizan para ilustrar la cultura educativa responden precisamente a la intención de dar visibilidad a las ritualidades de la escuela y a sus representaciones. El análisis histórico de estas iconografías, que poseen unos elementos reales y otros ficticios, es el que, como señaló Pierre Bourdieu, permite comprender el significado y el sentido de las representaciones, así como la apropiación de estas por parte de los sujetos que analizan e interpretan los objetos simbólicos al tiempo que gozan estéticamente cuando los examinan y deconstruyen. El lector podría incluso hacer con estas lecturas de imágenes una especie de "desmontaje impío" en un ensayo por intentar descubrir lo serio a través del placer de jugar con los iconos y de participar en la ilusión que comporta analizar, entender e interpretar toda ficción (Bourdieu, 1995, pp. 483-484).

La deconstrucción de las representaciones, la que se opera en los procesos de recepción que hace el historiador, o en los que llevan a cabo los públicos que visitan los museos y las exposiciones que muestran el pasado de la escuela, ofrece la posibilidad de abrir el sentido de la interpretación hacia nuevos horizontes de comprensión, de amplio y diversificado espectro semántico. Tal estrategia puede acercar igualmente a los analistas a una comprensión amplia y plural de las prácticas cotidianas escolares y de los rituales comunitarios que las acompañan, lo que además ofrece la posibilidad de poder potenciar el efecto educador de las construcciones históricas en las que se muestra y comunica la cultura empírica de la educación, basada en la experiencia.

\section{Rituales y emociones}

La historia de la educación se ha incorporado recientemente a los enfoques y contribuciones de la historia de las emociones. Resulta sorprendente que no lo hubiera hecho antes, cuando como es bien sabido el mundo de la afectividad ha sido de hecho un elemento sustantivo en la constitución de la educación, y en la construcción de la subjetividad. Más 
aún, los rituales de la escuela se han construido en gran medida para encauzar el pathos de los sujetos en formación y las conductas afectivas que ejercen los actores de la escuela, y de este modo para regular los procesos de socialización que se llevan a cabo en las instituciones.

Por otra parte, todos recordamos la escuela como un espacio real y metafórico del mundo de nuestra vida infantil y adolescente, de cuya memoria emergen anclajes afectivos que transforman la experiencia vivida en fuente esencial de nuestra propia identidad narrativa. El tiempo deviene tiempo humano -escribió el filósofo Paul Ricoeur - en la medida en que se articula y expresa bajo la forma de relato o narratorio sustentado en buena parte en la educación sentimental recibida (Ricoeur, 1996). Y los seres humanos dan sentido al mundo - se reafirmaba el psicólogo Jerome Bruner - contando historias, o sea, usando el modo narrativo de construir la realidad, una práctica discursiva que es en parte una actitud de rebelión frente al racionalismo dominante en los modelos comunitarios al uso, porque en ella afloraban siempre las emociones que se asocian a la experiencia vivida (Bruner, p. 149). Esta recuperación de la memoria también ha adoptado formas ritualizadas, es decir, modos de expresión que en ocasiones reflejan la educación sentimental sufrida o recibida con lenguajes no exentos de retórica, y en otras lo hacen de manera pasteurizada, transformando la realidad vivida en lenguajes rituales que la hagan más asumible o presentable en sociedad.

La inmersión escolar es un hecho que afecta al mundo emocional. Desde la salida del niño del nicho ecológico y protector de la familia, y a lo largo de todo el proceso de la segunda socialización que ofrece la escuela, el menor -que se metamorfosea en ella convirtiéndose en alumno mediante procesos ritualizados - se ve sometido al juego que sobre él ejercen los diversos climas y dispositivos de control afectivo que pone en acción el biopoder pedagógico que comportan los mecanismos de la formación: la ergonomía de los nuevos espacios y enseres muebles; los biorritmos de los cronos institucionales que se superponen a los domésticos; los códigos de la urbanidad, la disciplina y el ceremonial que rigen la gobernanza en la educación; las sutilezas del pudor, de la seducción y del humor que acompañan a los lenguajes educativos; las estructuras textuales de los manuales y las reglas normativas de la escritura; los mensajes de la iconografía con que se inundan los ámbitos institucionales... Todos los elementos que definen el régimen escolar comportan, cada uno por separado y como conjunto, una semántica y unos modos litúrgicos o formales que ejercen sobre toda la infancia una educación sentimental bien definida y de influencia duradera, que con el pasar del tiempo reaparece en los recuerdos de los adultos.

La reconstrucción de la memoria, que se lleva a cabo en determinadas circunstancias biográficas, también adopta a menudo formas rituales de expresión. Este trasfondo cargado de afectividad no solo acompaña a los elementos cognitivos de la formación; potencia o neutraliza asimismo otros mecanismos más complejos. Con ello, las vivencias emocionales contribuyen a conformar la subjetividad humana, lo que se manifiesta cuando aflora en el 
narratorio de las biografías cualquier estímulo que activa la memoria. Ello es así porque la cultura de la escuela es, a fin de cuentas, un conjunto holístico de cogniciones y emociones en interacción. Al sonar una canción aprendida en la infancia, como las relacionadas con algún ritual, se activa una emoción antigua que está integrada en el palimpsesto de los recuerdos, nuestro sustrato antropológico profundo. Lo mismo sucede, por ejemplo, al encontrarnos con la cartilla en la que comenzamos a leer las letras del alfabeto o el cuaderno en el que dejamos registro gráfico de nuestras primeras huellas escribanas (u otros aprendizajes iniciáticos como el cálculo aritmético o el catecismo). Y por supuesto, algo dejaron en nuestra sociabilidad afectiva los pares o compañeros de edad con los que cohabitamos durante años en las aulas y en los patios de recreo, o los enseñantes que nos educaron, apercibieron, premiaron o castigaron. Nadie olvida desde luego un buen maestro, ni tampoco a un dómine disciplinante.

Algunos de los dispositivos que controlan y encauzan la afectividad de los sujetos educandos se sirven, de modo más expreso, de procesos y lenguajes que se adscriben a las ritualidades. Veamos dos de ellos: el ludus y la urbanidad. El primero encauza los impulsos infantiles primarios bajo formas de socialización que comportan control, catarsis y aprendizaje social. La urbanidad, que como se sabe llegó a constituirse en la escuela como una disciplina del currículum, además de como una práctica de sociabilidad, responde a una modalidad de cultural esencialmente ritual, tanto en sus contenidos como en sus métodos.

\section{a) Juego/ludus}

El juego, en sus diversas modalidades, domésticas, informales e institucionales, ha sido un importante dispositivo regulador del mundo afectivo de la infancia y del aprendizaje social. Muchas pedagogías, algunas incluso tradicionales, pero sobre todo las modernas, se han apoyado en el papel del ludus como método de socialización de las emociones, así como de ejercitación de los rituales necesarios para la integración de los sujetos en los modos de convivencia de los grupos infantiles y en la misma comunidad. El juego ha sido transferido asimismo a los modelos de aprendizaje motor y cognitivo, esto es, a los métodos en enseñanza y de aprendizaje. Todo método implica en su estructura y funcionamiento un protocolo de pasos a seguir según ciertas reglas y también con algunos grados de libertad.

A diferencia de otros dispositivos de control emocional, basados sobre todo en estrategias de disciplina y gobierno, en su mayor parte de extracción externa, el juego -como la urbanidad y los rituales - opera siempre mediante la aplicación de códigos sociales asumidos por el grupo, en ocasiones de gran rigor formal en su ejecución y en su verificación. Solo se puede jugar correctamente si se respetan las reglas de la actividad. Un ritual asumido en comunidad no puede romper sus códigos. 
Como se recordará, fue Roger Caillois uno de los más acreditados analistas de los juegos en sociedad. Los menores han practicado las cuatro modalidades de las que habló el tratadista francés, que se utilizaron para desarrollar habilidades sociales y para controlar los afectos, también en la escuela. Una de ellas, la mimicry, alude a los juegos de imitación, tan esenciales en el desarrollo intelectual y afectivo de los niños. Otra, denominada alea, se refiere a los juegos de azar, igualmente presente en las interacciones lúdicas y emotivas del mundo infantil. Una tercera corresponde al agon, con sus componentes de lucha y competición. Finalmente, la cuarta modalidad se relaciona con los juegos de riesgo y vértigo, el ilinx, menos frecuentes en la infancia, aunque operantes en la adolescencia como pruebas de afirmación e identidad del yo (Callois). Todos estos tipos de ludus se practican conforme a ciertos códigos formales y a un ethos de base que los fundamenta y los sostiene. Y todos ellos se han introducido, de una u otra forma, en la cultura de la escuela, ya sea en sus prácticas formales o en las actividades no formales que se desarrollan con la infancia escolarizada.

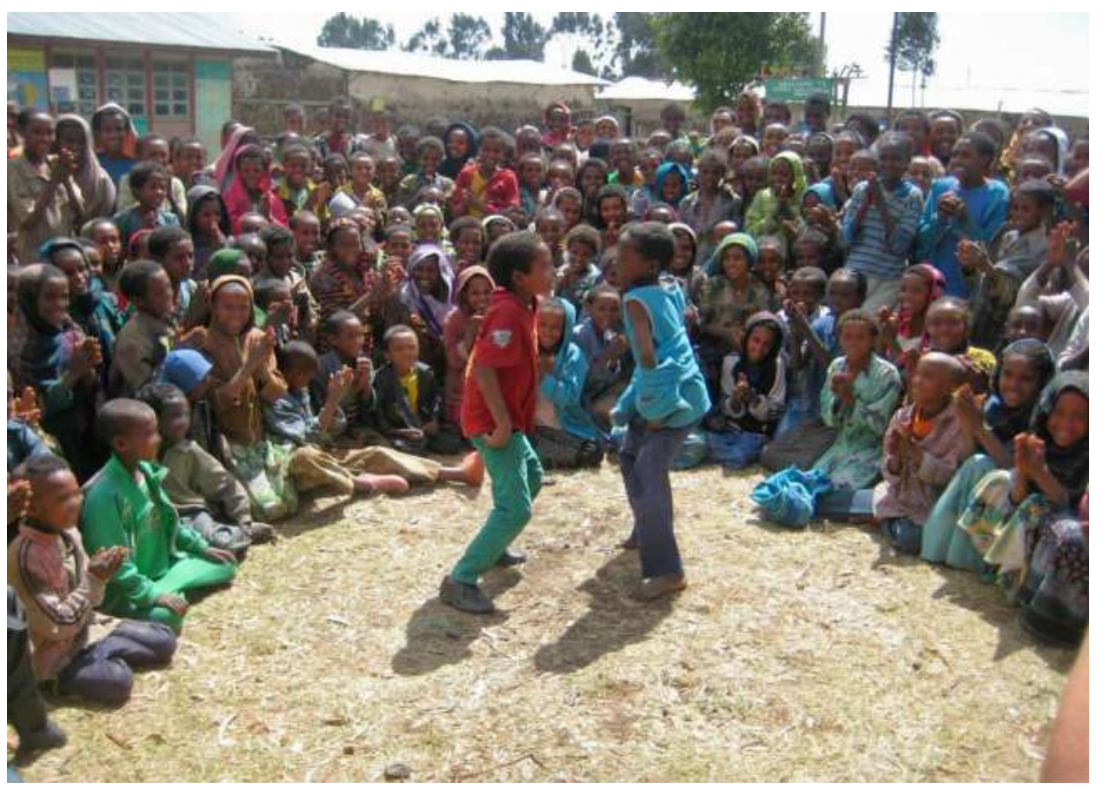

Imagen 6. Escuela rural de Malindi, Kenia, 2007

\section{JUEGO Y LUCHA}

La lucha y la competición son modalidades lúdicas que se ejercitan de modo ritual en las prácticas de socialización informal y formal de los menores en todas las comunidades, en las tradicionales y en las modernas. 
La imagen corresponde a una escena tomada en 2007 en la aldea rural de Malindi, de Kenia, junto a la escuela del lugar (cedida por cortesía de nuestra colega Nuria Villa).

En élla, como en las experiencias que describe el antropólogo Clifford Geertz, dos niños interaccionan bajo forma de lucha, juego y dramatización, mientras toda la comunidad participa en la ceremonia, en un escenario público y abierto.

En este juego agonístico se aprende que la vida es lucha y que incluso en la escuela la convivencia es conflicto y competición, dos hechos de aprendizaje y control social que se internalizan mediante estos juegos rituales.

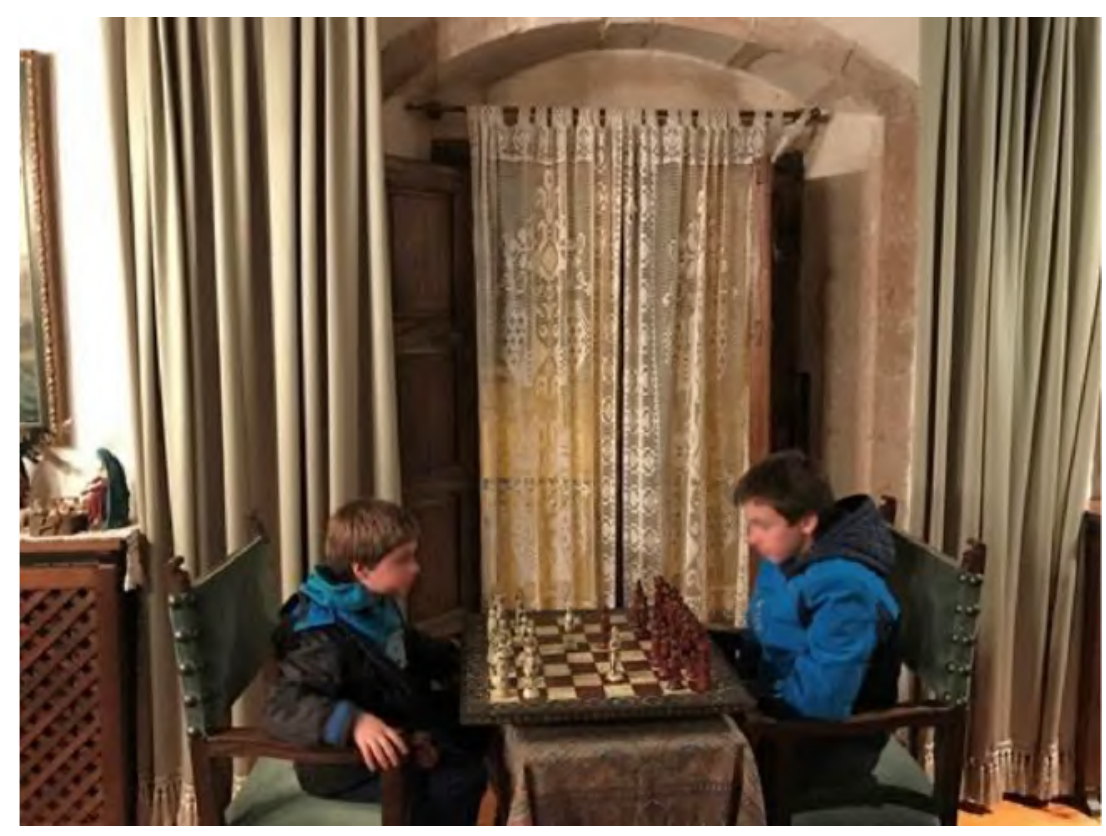

Imagen 7. Juego de ajedrez

\section{APRENDER A COMPETIR}

Martín aprende a competir jugando al ajedrez con su hermano Pablo. Ambos mantienen una gran atención y adoptan actitudes muy serias. El juego es divertido pero también exigente.

El ajedrez es un juego con reglas formales muy estrictas y puede ser visto como una metáfora lúdica de la lucha y de la competición. 
El aprendizaje se lleva acabo a menudo entre pares de edad en situaciones de juego y convivencia no formal pero con gran respeto a las reglas. En él se pone en juego también el control de la subjetividad conforme a normas externas.

Esta práctica, pues, aún siendo lúdica, ha de ser ejercida con rigor porque en ella se representan actitudes que implican a los individuos como sujetos sociales.

Los juegos de combate, que pueden parecer comportamientos agresivos, y que en todo caso son los más impulsivos, son expresión del instinto luchador, tal como interpretó Pierre Bovet al examinar el papel desempeñado por este mecanismo psicofísico en la evolución de la especie y en el mismo desarrollo infantil, tomando como base de análisis la compilación de más de mil juegos que había efectuado Karl Groos (Bovet, p. 22). Desde los juegos de lucha a las competiciones y certámenes sociales y escolares hay muchas modalidades de actividad que se podrían incluir también en las categorías del agon y el ilinx de los que habla Roger Callois. Todos estos patrones lúdicos han tenido presencia en las escuelas de todos los tiempos y están por tanto integrados en la cultura histórica de la educación, y también en la actual, que es igualmente histórica. Aunque sufran cambios en su técnica y en su operatividad, el núcleo duro en que se sustentan los juegos, al estar informado por una impronta de carácter ritual, tiende a reproducirse y a permanecer como invariante sociopedagógica en la pragmática de la educación.

\section{b) Urbanidad.}

La urbanidad es otro de los patrones de control emocional sujeto a reglas, tal vez el ámbito más ritualizado de la educación formal y no formal. Incoada como disciplina del programa formativo en los tratados de la primera Modernidad, de los cuales el de Erasmo es siempre un referente esencial, la urbanidad está en el origen mismo del despegue del nuevo proceso civilizatorio que se desarrolla a través de los siglos modernos, tal como mostró hace años el sociólogo alemán Norbert Elias en un estudio que se ha hecho de citación inexcusable en la materia (Elias).

Los modos de urbanidad, difundidos desde el siglo XIX en la escuela por medio de cartillas ad hoc, al igual que los métodos y los procesos de alfabetización letrada, pueden ser entendidos como ortopedias que se superponen a la libre espontaneidad de los sujetos, y de modo más expreso a su emotividad. A partir del Renacimiento, la escuela y la sociedad han venido pautando determinados modelos de comportamiento cívico que se han instalado en el imaginario colectivo como patrones normalizados de sociabilidad. Estos códigos, que las cartillas de urbanidad trasladaron a las escuelas, tuvieron como finalidad regular la conducta de los sujetos conforme a un determinado canon social impuesto por las clases dominantes de la sociedad burguesa, que por entonces se afirmaban frente a los estamentos de la sociedad 
cortesana, si bien la nobleza participaría de este mismo código de normalización y de disciplina. La urbanidad podía incluso, como señalaba la tratadista Pilar de Sanjuán, evitar las penitencias severas que imponían a los niños las leyes civiles en los casos de desacato a la autoridad civil, familiar o escolar (Sanjuán, p. 77). Y además podía transmitirse de forma metódica y ritual a través de las escuelas.

La imagen que ilustra este nuevo dispositivo de encauzamiento de la conducta de la infancia procede de un conocido manual de urbanidad, el más difundido tal vez en la escuela española del siglo pasado: la cartilla de urbanidad de la casa editorial Luis Vives (FTD). Se muestra seguidamente una viñeta - diseñada por el acreditado dibujante Alfredo Opisso- que alude a determinado tipo de comportamiento que los niños debían practicar con el debido respeto a los mayores: la humildad. El ejemplo que aquí se reproduce se refiere al ámbito de la escuela, aunque todos los textos didácticos de urbanidad cubren generalmente todos los aspectos de la vida social en que se ve envuelta la vida de la infancia: la familia, la calle, la iglesia y otros espacios de sociabilidad.

LO MAS HERMOSO DEL NIRO

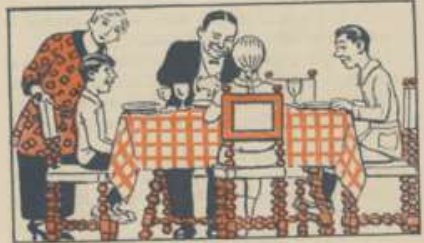

Fetar eatidfecho coe fa que dispones los papds

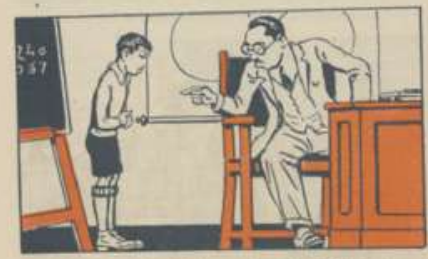

Recibir con humilidad correccianes $y$ reprimendas

$-80$
LO MAS FEO DEL NHNO

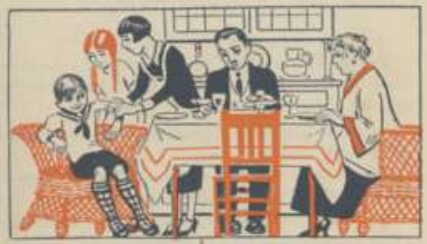

Desobedecer y abochornar a lon pephe

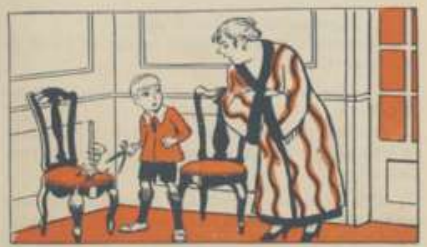

Rafadarae cuando le corriken

$-51-$

Imagen 8. Cartilla de Urbanidad, 1927 


\section{URBANIDAD COMO RITUAL}

Viñetas verboicónicas procedente de la Cartilla de urbanidad editada en España por la casa Luis Vives en 1927.

Texto e imagen se implementan para transmitir al lector un mensaje de manera eficiente.

En la escena se pueden ver varias situaciones en las que el niño puede sentir emociones de diverso signo: satisfacción - humildad - vergüenza - enfado.

Las cartillas de urbanidad ofrecían en viñetas seriadas una imagen real de las normas que habían de regular la conducta en diversas situaciones en las que los niños se verían implicados (familia, calle, escuela, iglesia, mesa...)

Es interesante remarcar que este tipo de manual es innovador no solo por los contenidos que acoge sino por los modos textuales de presentación, que por primera vez combinan de forma integrada y sistémica el lenguaje verbal con el icónico, trasladando a la infancia modelos a reconocer e imitar en sus prescripciones normativas. La imitación es tal vez la conducta más ritualizada de las que forman parte de la cultura empírica de la escuela. Con cierta estética lúdica, aunque sin abandonar la intencionalidad moralizante, las cartillas de urbanidad mimetizaban a la vez otros patrones verboicónicos como los utilizados en las historietas, los comics y hasta los tradicionales pliegos de cordel adscritos a la literatura popular.

\section{Culturas y rituales escolares en interacción}

El reformismo escolar, que Pedro Roselló categorizó en 1960 como una "corriente educativa" en alza en el mapping que trazó él mismo desde el observatorio de la Oficina Internacional de Educación de Ginebra (Roselló) se ha universalizado hoy. Podría en parte afirmarse que observando el hecho de que unas reformas se suceden a otras en tiempos cortos, como unas vanguardias desplazan a las que le precedieron, en una especie de cadena sin fin, que el reformismo educativo se habría convertido hoy en una actitud ritual que asumen las agencias que promueven los cambios. Las innovaciones educativas se instrumentan en la actualidad de forma retórica, con frecuencia sin las exigencias de la crítica, siguiendo el ritmo que impulsan los cambios políticos y administrativos, y aun a veces las modas pedagógicas. Por la duración ya secular de estos procesos se puede concluir que el reformismo constituye una corriente establecida y ritualizada. 
Desde otra perspectiva, la práctica de las escuelas y los enseñantes, por su sedimentación histórica, también se ha fijado conforme a pautas rituales. Las instituciones, por su misma naturaleza de organizaciones consolidadas, tienden a fijar sus estructuras y modos de funcionamiento adoptando fácilmente los rituales en los que se materializa la tradición. Y los enseñantes adoptan igualmente patrones de conducta profesional que son conservadores con relación a los códigos del oficio que asume la corporación. Este componente ritual de la tradición no es compatible con el sentido hiperactivo de las estrategias de cambio en la sociedad de nuestro tiempo.

Las culturas externas de la escuela -la académica y la normativa- han influido en la configuración institucional del mundo educativo de la experiencia, encarnándose históricamente esta interacción en determinadas formas de organización de la acción educativa y en los hábitos de los docentes. Fue en la experiencia donde se condensó históricamente la memoria de la cultura pragmática de los modos de enseñanza y aprendizaje, incluyendo en esta praxis la fuerte estructuración ritual que acompañó a los procesos fundamentales de interacción y socialización de los hechos culturales vinculados a la vida escolar. No es extraño, pues, que la ritualidad sea una condición inherente a la mayor parte de las prácticas habituales dominantes en la escuela.

Si a esta tradición se suma la retórica del reformismo escolar advertida en el comienzo de este punto, la cultura y la vida de las escuelas se vería sometida hoy al estrés derivado del cruce de dos estrategias rituales: la de la costumbre y la de la innovación. De la coexistencia de ambas es difícil lograr una fusión o una interacción verdaderamente reformadora, toda vez que incluso son difícilmente compatibles en los mismos lenguajes en que se expresan. Más bien se operaría en este juego una dialéctica de cohabitación incómoda, toda vez que no es fácil integrar las rutinas que portan los usos establecidos con las propuestas de la innovación que proceden del juego retórico de las vanguardias.

A los efectos de lo que aquí se estudia, resulta de interés comprobar cómo, por ejemplo, las reformas administrativas de la enseñanza utilizan categorías y conceptos que proceden del ámbito académico, con lo que tales propuestas innovadoras atribuyen valor de modernidad y cientificidad a los programas de cambio. Esta sería una estrategia de seducción o persuasión orientada a presentar a los prácticos las innovaciones como producciones derivadas de la lógica del progreso. También es posible constatar cómo los discursos pedagógicos que formulan los teóricos se ponen en ocasiones al servicio de las burocracias del sistema, configurándose de este modo sus autores y círculos intelectuales como pedagogos orgánicos o como grupos o lobbies de influencia. Esta podría ser también una estrategia interesada de legitimación académica. No obstante, tanto las operaciones de seducción como las de legitimación no contemplan con rigor suficiente la lógica ritual de la cultura pragmática de las instituciones y de las rutinas de los enseñantes. Muchos de los fracasos de las reformas 
derivan justamente de esta falta de comprensión de las resistencias de la cultura escolar en el plano empírico, que vienen en gran parte condicionadas por el régimen de los rituales que subyace en esta cultura.

En la realidad, las tradiciones e innovaciones se han fundido muchas veces en modelos de carácter sincrético. La historia educativa pone de manifiesto, como ha destacado la profesora Diana Gonçalves Vidal, los procesos de "hibridación cultural" que se propician cuando se construyen las prácticas escolares, que nunca son puras, sino más bien el resultado de mestizajes que los sujetos producen al cruzar influjos muy heterogéneos procedentes de diversos circuitos pedagógicos, a partir de los cuales se definen las distintas identidades (Vidal). En estos cruces se operan a veces cambios o readaptaciones de las ritualidades vigentes entre los colectivos que se apropian de las innovaciones, si bien algunos patterns fuertemente ritualizados siguen persistiendo, como registros estables de la memoria, en las prácticas resultantes de los procesos de interacción.

En este orden de cosas, interesa profundizar en las posibilidades de investigación etnográfica de los procesos reales de adaptación y apropiación que los docentes han llevado a cabo en el mundo escolar de las propuestas de cambio promovidas desde la esfera política, y en cómo las respuestas de los enseñantes han contribuido a construir en el plano de lo real el arte experiencial de la enseñanza y el oficio de profesor, esto es, lo que aquí hemos venido definiendo como cultura empírica de la escuela.

La historia de la escuela es una historia de creaciones, pero también es una historia de recepciones, acomodaciones, traducciones, apropiaciones, rechazos, resistencias, fusiones, mestizajes, metamorfosis. Y la historia de la profesión docente es además la historia de cómo los actores reales que encarnan estos comportamientos que informan la vida cotidiana en las instituciones de enseñanza, excluidos de los juegos de verdad que impuso el positivismo -en lo académico- y el estatismo -en lo político-, han ido construyendo empíricamente un arte con el que legitimar, desde la propia práctica de la educación escolar y con las ritualidades que confieren identidad, el protagonismo social y cultural de los enseñantes y las señas o marcas de su propio oficio. Esta es por lo demás, guste o no, la cultura efectiva resultante, esto es, la cultura realmente constituida en realidad de la que los historiadores hemos de ocuparnos prioritariamente. Y para ello la nueva historia ha de mantener un comercio activo con la etnología, la antropología y demás ciencias sociales, disciplinas que permitirán profundizar en la comprensión de los mecanismos que rigen los rituales que afectan a las culturas de la escuela. 


\section{Fuentes}

Tony Becher, Tribus y territorios académicos. La indagación intelectual y las culturas de las disciplinas,

Barcelona, Gedisa, 2001.

Pierre Bourdieu, Las reglas del arte. Cénesis y estructura del campo literario, Barcelona, Anagrama, 1995.

Pierre Bourdieu, El sentido práctico, Buenos Aires, Siglo XXI, 2007.

Pierre Bovet, El instinto luchador, Madrid, Francisco Beltrán, 1922

Jerome Bruner, La educación, puerta de la cultura, Madrid, Visor, 2000.

Randall Collins, Cadenas de rituales en interacción, Barcelona, Anthropos, 2009.

Norbert Elias, El proceso de la civilización. Investigaciones sociogenéticas y psicogenéticas, México, FCE, 1987 (edición original de 1977)

Agustín Escolano: "La cultura empírica de la escuela. Aproximación etnohistórica y hermenéutica", en Juan Mainer (ed.): Pensar críticamente la educación, Zaragoza, Prensas de Zaragoza, 2008, pp. 158-159.

Narciso de Gabriel: "Clases populares y culturas escolares", en Juan GÓMEZ et alt. (eds): La escuela y sus escenarios (Actas del Coloquio SPICAE), Puerto de Santa María-Cádiz, Publicaciones del Ayuntamiento, 2007, pp. 243-268.

Erving Goffman, Rituales de interacción, Buenos Aires, Tiempo Contemporáneo, 1970

Jack Goody: Representaciones y contradicciones, Barcelona, Paidós, 1999.

Edmund Leach, Cultura y comunicación. La lógica de la conexión de los símbolos, Madrid, Siglo XXI, 1978.

Paul Ricoeur, Tiempo y narración III. El tiempo narrado, México, Siglo XXI, 1996.

Richard Sennett, El artesano, Barcelona, Anagrama, 2009

Richard Sennett, Juntos. Rituales, placeres y política de cooperación, Barcelona, Anagrama, 2012.

Richard Sennet, Construir y habitar, Barcelona, Anagrama, 2019.

Aida Terrón y Violeta Núñez: "Sobre la cultura escolar y los mitos en nuestra escuela", Cultura y Educación, 14.3, 2002, pp. 237-252

Roger Callois, Los juegos y los hombres, México, Fondo de Cultura Económica, 1986.

Diana Gonçalves Vidal, "Cultura e prácticas escolares: a escola pública brasileira como objeto de pesquisa", Historia de la Educación, 25, 2006.

Daniel Pennac, Mal de escuela, Barcelona, Mondadori, 2008, pp. 47-51.

Stefan Zweig, El mundo de ayer. Memorias de un europeo, Barcelona, Acantilado, 2022, p. 26.

Richard Sennett, El artesano, Barcelona, Anagrama, 2009, p. 21 ss. También: Richard Sennett, Juntos.

Rituales, placeres y política de cooperación, Barcelona, Anagrama, 2012.

Richard Sennett, Construir y habitar, Barcelona, Anagrama, 2019. 